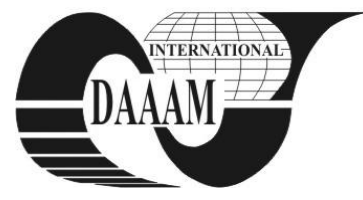

Annals of DAAAM for 2011 \& Proceedings of the 22nd International DAAAM Symposium, Volume 22, No. 1, ISSN 1726-9679 ISBN 978-3-901509-83-4, Editor B. Katalinic, Published by DAAAM International, Vienna, Austria, EU, 2011 Make Harmony between Technology and Nature, and Your Mind will Fly Free as a Bird

\title{
USAGE OF SIMULATION IN INVENTORY MANAGEMENT EDUCATION
}

\author{
KNEZEVIC, B[lazenka]
}

\begin{abstract}
The level of inventories directly affects performance of a company and directly influences firms' profitability. The aim of simulation games is to overcome potential losses that occur when the method of "learning by doing" is implemented. Simulation games are well accepted method of learning in the student population. In this paper the usage of the simulation model in the area of inventory management will be described. The simulation model is developed according to the stock management principles, implemented in Excel and used within practical education at University level.
\end{abstract}

Key words: inventory management, stock optimization, simulation model, simulation, educations

\section{INTRODUCTION}

In business schools and universities case studies are recognized as a good tool for knowledge transfer regarding logistic practices for a longer period, but simulation games are introduced in the mid 50ties when Monopologs was used to teach purchasing management in US Airforce (see Faria and Dickinson, 1994).

New student generations are using various ICT tools for different purposes such as: entertainment, socialization, gaming, learning, research and shopping. Thus, they are very open to computer simulations as a learning tool. Simulation games are based on simulation models which are built according to some real situation or to some real problem (for example see Folcut et al, 2008). Implementation of simulation models in educational process brings us closer to the concept of risk-free "learning by doing" situation.

There are numerous benefits of simulation games quoted in the literature. For instance, Ruohomaki (1995) states that simulation games in education ensure (1) positive learning results in terms of information transfer, rules observation and critical review, (2) shift of the attitude regarding the object of the simulation process and society, (3) increased motivation and interest for the researched area, and (4) improved group dynamics.

Knezevic (2008) observed positive attitudes of students towards implemented simulation games at the Procurement management course. Students pointed out that simulation games are more interesting than ex-cathedra teaching and case studies. Moreover, simulation games are evaluated as challenging and motivating way of learning. An iterative simulation process is seen as a source of better understanding of the key concepts in the given area of simulation.

In this paper the practical usage of one simulation model in the field of inventory management will be described.

\section{THE CONCEPTUAL FRAMEWORK}

The key terminology in the inventory management includes: stock level, demand in given period, costs of ordering, costs of warehousing, costs of stockout, lead time, order quantity and reorder point.

The level of demand in some period is measured in terms of quantities needed by consumers. It is usually very stochastic and hard to predict.

A stock level is the term used for quantity of stocks kept in company's warehouse in some given period. Usually companies determine the minimum level of stocks according to the formula: Minimum stock level $=$ Reorder level or ordering point - Average usage for Normal period.

Costs of warehousing or holding costs depend on quantity kept in stock, they include: cost of personnel in the warehouse, cost of warehousing space and equipment used to maintain the required level of goods' quality.

Costs of ordering do not directly depend on ordered quantity. Those are fixed costs of the ordering process per one order.

Stockout costs are the costs of lost opportunity, they occur when there is unsatisfied demand in some period. Their rough approximation is a lost sale in the given period.

The lead time is the time needed for obtaining new stocks. It depends on terms and conditions previously set up with suppliers, but they depend on particular situations regarding transport infrastructure as well.

The order quantity is the quantity of goods that company is ordering from its supplier. From the point of view of the company, it is fully controllable variable even in the short time.

The reorder point is the level of stock implemented into information system of a company that alerts company to place an order. The reorder point is determined by a company with the purpose to ensure continuity of production and delivery to consumers. The most common way to calculate the reorder stock level is: Reorder level $=$ Average daily usage rate $\mathrm{x}$ leadtime in days.

\section{THE MODEL DESCRIPTION}

The model was developed in Microsoft Excel. The first step of the model development was recognizing and setting of stochastic variables. Two stochastic variables were implemented into the model: (1) demand and (2) lead time. For both variables RANDOM function was used for generating randomized distribution while some limitations were set up. For the lead time maximum and minimum levels were defined and probability tables were used to describe consumer behaviour (i.e. daily demand level).

The quantity model was developed in order to explain what happens in one month period on a daily basis. The observed quantity levels for each day in a month included: (1) starting inventory, (2) received goods, (3) available inventory, (5) end inventory, and (4) stockout level occurred.

Finnaly, formulas for cost calculation were added to the model. There are three types of costs in the model: (1) holding costs calculated as given unit costs times end inventory, (2) stockout costs calculated as given unit costs times stockout level occurred, and (3) ordering costs which are calculated if 
the end inventory is below the re-order point defined at the beginning of the simulation. Total costs are also calculated and placed into the separated column.

The initial values are set up as following: 700 starting inventory; max. lead time 5; min. lead time 1 ; holding costs per unit per day $\$ 0,45$; stock out cost per unit $\$ 30,00$ and order costs per order $\$ 50,00$. The order quantity (Q) was set to 3000 and the reorder point to 300 units. The first simulation iteration was calculated before the class and it resulted in following monthly costs: holding costs $\$ 11.115,00$; stockout costs $\$ 60.000,00$; ordering costs $\$ 100,00$ which is the total of $\$ 71.215,00$.

\section{IN-CLASS IMPLEMENTATION}

All key equations implemented into Excel model were explained to students. Secondly, students were asked to perform a new iteration of simulation and four students were asked to transfer their monthly costs onto the blackboard. Then the influence of the stochastic variables was discussed and some preliminary conclusions were drawn out. After that, students were asked to add the DATA TABLE option in order to make 500 observations available for the further analysis. The process of the table creation was described in details. Students ran several iterations and observed changes in the Data table. After that, students had to calculate averages for the each cost type in the given number of observations (500). In addition, they are asked to use basic statistical formulas to produce the table as shown at Tab.1 and to draw a graph as shown at Fig. 1.

\begin{tabular}{|l|r|r|r|r|}
\hline \multicolumn{1}{|c|}{ Holding } & \multicolumn{1}{l|}{ Stockout } & \multicolumn{1}{l|}{ Ordering } & \multicolumn{1}{l|}{ Total } \\
\hline max & $20.295,00$ & $105.000,00$ & 150,00 & $115.045,00$ \\
\hline min & $7.965,00$ & $3.000,00$ & 100,00 & $16.560,00$ \\
\hline mean & $12.528,00$ & $40.686,00$ & 110,40 & $53.324,40$ \\
\hline stdev & $1.418,69$ & $18.694,55$ & 20,31 & $17.853,88$ \\
\hline mode & $12.915,00$ & $36.000,00$ & 100,00 & $44.320,00$ \\
\hline
\end{tabular}

Tab. 1. Statistic indicators for 500 observations

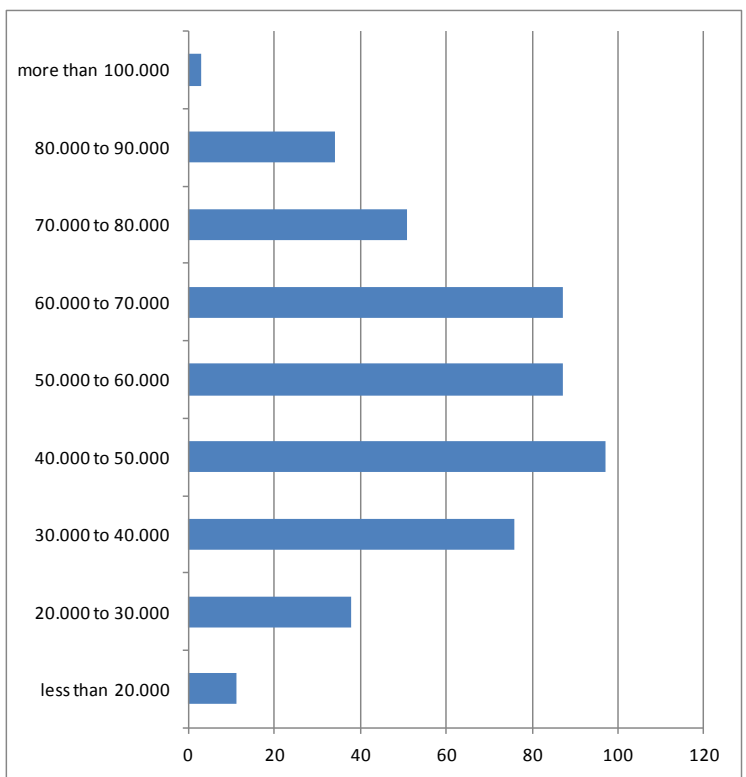

Fig. 1. Frequencies according to total cost levels in $\$(n=500)$

After the simulation, students were divided into teams of 4 members and they had to discuss the cost structure at this particular model and to recommend a strategy to lower inventory costs of the company. Students had an opportunity to do several simulation repetitions or to test their ideas throughout model modifications by changing different variables at the copy of the simulation model. At the end of the class they had to deliver a report with a clear recommendation of steps supported by the data analysis.

\section{UPGRADE OF MODEL (SCENARIO TESTING)}

At the next class a review of team papers was done and scenario analysis was performed. Initially, 6 scenarios were tested via WHAT-IF Excel tool. Results of scenarios are shown at Tab. 2.

\begin{tabular}{|l|r|r|r|}
\hline & Scenario 1 & Scenario 2 & Scenario 3 \\
\hline Order quantitiy & 5000 & 3000 & 5000 \\
\hline Re-ordering point & 500 & 500 & 300 \\
\hline Holding costs & $23.466,60$ & $13.388,40$ & $21.618,27$ \\
\hline Stockout costs & $25.272,00$ & $31.812,00$ & $31.068,00$ \\
\hline Ordering costs & 99,40 & 121,90 & 95,00 \\
\hline Total costs & $48.346,03$ & $44.609,07$ & $54.729,08$ \\
\hline & Scenario 4 & Scenario 5 & Scenario 6 \\
\hline Order quantitiy & 1000 & 3000 & 1000 \\
\hline Re-ordering point & 300 & 100 & 100 \\
\hline Holding costs & $2.629,08$ & $11.880,09$ & $2.363,13$ \\
\hline Stockout costs & $83.328,00$ & $52.506,00$ & $93.876,00$ \\
\hline Ordering costs & 227,50 & 103,60 & 200,20 \\
\hline Total costs & $82.818,84$ & $62.829,03$ & $97.148,45$ \\
\hline
\end{tabular}

Tab. 2. Results of the Scenario analysis

Two out of six scenarios had similar total costs. Those were scenario with the order quantity of 5000 and the re-ordering point of 500 and scenario with the order quantity of 3000 and the reordering point of 500. Therefore, before the final decision, students had to implement those quantity levels directly into the simulation model and run simulation again in order to scrutinize each option. The teams of four had to work together and test more scenarios as a homework assignment. That assignement was an introduction to the wider and more complex theme of the economic order quantity concept (EOQ).

\section{CONCLUSION}

The implementation of simulation modelling together with the teamwork is a challenging task both for teacher and for students. Via simulation models students have an opportunity to test options in the risk-free environment. In the paper the way how to deliver 2 classes in the area of inventory management was suggested together with the homework assignement given as an introduction to the theme of the economic order quantity. The given example shows us how to implement simulation model of inventory management into the classroom of a business school and how to transfer knowledge on inventory management concepts and advanced Excel usage as well.

\section{REFERENCES}

Faria A.J. and Dickinson, J.R. (1994); Simulation gaming for sales management, Journal of management development, Vol. 13, No.1, pp. 47-59, ISSN 0262-1711

Folcut, O.; Ciocirlan, D. \& Mustea Serban, R. (2008). Simulation Model for the Financing Strategies of a Leasing Company, Annals of DAAAM for 2008 \& Proceedings of the 19th International DAAAM Symposium, 22-25th October 2008, Trnava, Slovakia, ISSN 1726-9679, ISBN 978-3-901509-68-1, Katalinic, B. (Ed.), pp. 0481-0482, Published by DAAAM International Vienna, Vienna

Knezevic, B. (2008); The evaluation of simulation games applicability for better understanding supply chain principles, Poslovna logistika u suvremenom menadžmentu, Segetlija, Z. (ed.), Faculty of Economics Osijek, Croatia, pp. 95-110, ISBN 978-953-253-052-0 (in Croatian)

Ruohomaki, V. (1995); Viewpoints on Learning and education with simulation games, in J. O. Riis (ed.), Simulation Games and Learning in Production Management, Chapman and Hall, pp. 13-25, ISBN 0-412-72100-7 